\title{
Making Sense of the Aggregator Bank
}

\section{LAWRENCE M. AUSUBEL AND PETER CRAMTON}

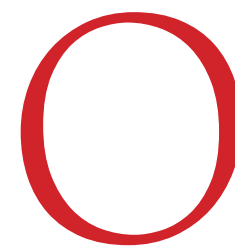

n Tuesday, 10 February 2009, Treasury Secretary Geithner proposed the aggregator bank ("public-private investment fund") as a key instrument to resolve the financial crisis. The Treasury description leaves many issues unanswered. So how might an aggregator bank operate in practice? We fill in some of the major details so as to enhance the effectiveness of the aggregator bank. In particular, our approach emphasizes transparency and value to the taxpayer, mini-

Lawrence M. Ausubel and Peter Cramton are Professors of Economics at the University of Maryland. Their auction proposal and experiments relating to troubled assets have received the attention of the Treasury and policy makers, and can be found at www.ausubel.com and www.cramton.umd.edu. mizing the need for bank-by-bank negotiations and thereby minimizing the opportunities for the government to play favorites, or to appear to play favorites.

For concreteness we use specific numbers for the various parameters in the plan. These are for illustration purposes only; the actual numbers would be set by the Treasury after careful analysis.

The aggregator bank is a vehicle to remove toxic securities from banks so that the banks' remaining balance sheets have a readily-assessable value, enabling investors and counterparties to be confident that solvent banks are indeed solvent. To limit the size of the public investment and to avoid putting trillions of dollars in mortgage securities directly in government hands, the aggregator bank obtains private capital to supplement government capital, and it operates under a blend of public and private control.

ESSENTIAL ELEMENTS OF THE AGGREGATOR BANK Rank qualification. Banks apply to participate $D_{\text {in the program. Participation comes with }}$ a number of obligations including a high level of disclosure. Banks that are in such bad shape that rescue is futile fail to qualify. These nonqualifying banks are handled through the standard process for taking over insolvent banks.

Securities to be purchased. The Treasury identifies the set of securities eligible for purchase by the aggregator bank. These include primary mortgage-related assets, but do not include derivatives of these securities, such as credit default swaps. Whole mortgages on 
bank balance sheets, not yet securitized, may be bundled into bank-specific securities, and may be included as well.

Security pools. The securities are grouped into a number of pools. Each security in a pool has similar default characteristics. Securities within a particular pool are close substitutes. The use of pools of related securities enhances price transparency and limits adverse selection.

Reference prices. Each security is given a reference price. This is the government's best estimate of the current value of the security as a percentage of the face value, that is, "centson-the-dollar." The reference prices are determined from all the observable characteristics of the security, state-of-the-art valuation models and, when available, recent comparable transactions. Reference prices are used to adjust for the relative differences in quality of securities within a pool.

Floor (guarantee). Each pool of securities is assigned a guaranteed floor, which limits the loss of the aggregator bank on the pool of securities. For example, if a pool has been assigned a $60 \%$ floor, this means that the aggregator bank has been granted a government guarantee that the value of the pool will not fall below $60 \%$ of its purchase price; that is, the total loss on the pool is limited to $40 \%$ of its purchase price.

Public capital. This is the maximum amount of the aggregator bank's public capitalization, assumed to be $\$ 50$ billion here, that is assigned to a given pool. For example, $\$ 10$ billion of public capital may be assigned to each of five security pools.

Private capital. This is the amount of capital offered by private investors, such as institutional investors, hedge funds and the general public, to assist in the purchase of a given pool at a given price. For example, private investors may offer $\$ 20$ billion of capital if the securities are purchased at $100 \%$ of the reference price, and this amount may increase to $\$ 30$ billion if the purchase price is $95 \%$ of the reference price. In economic terms, this is the private demand for the pool of securities.

Ownership. The public and private ownership shares of a security pool are in the same proportions as the public and private capital. Thus, if $\$ 10$ billion of public capital is allocated toward a given security pool and if the private sector offers $\$ 20$ billion of private capital for this pool then the public ownership share will be one-third and the private ownership share will be two-thirds. If necessary, the government limits public capital to assure that the public share remains below 50\%, to avoid holding a majority interest in the aggregator bank.

Leverage of aggregator bank. The aggregator bank will sell bonds to leverage its capital. The leverage of each pool is not allowed to exceed a specified multiple of its capital for the pool. The multiple may be higher for a safer security pool, and lower for a riskier security pool. For example, a low-risk pool may have a maximum leverage ratio of 8 , whereas a high-risk pool may have a maximum leverage ratio of 4 . The leveraged funds would come from bonds issued for the purpose. To further attract private capital, the government may facilitate the sale of the bonds through a subsidy of some kind, such as favorable lending terms.

Demand. Take the previous example of $\$ 10$ billion of public capital and $\$ 20$ billion of private capital at $100 \%$ of the reference price, and assume a leverage ratio of four-to-one for the particular security pool. Then the aggregator bank's demand for this pool is $(10+20) \times 4=\$ 120$ billion. If private capital increases to $\$ 30$ billion at a purchase price of $95 \%$ of the reference price, then the aggregator bank's demand increases 
to $(10+30) \times 4=\$ 160$ billion. The demand curve for each pool, including both private and public demand, is announced before the start of the pricing process for the particular pool. This announcement of demand motivates sellers to participate to sell their toxic securities.

Supply. Qualifying banks offer securities for sale in a competitive process. For each pool of securities, each bank offers a share of its holdings of the pool it desires to sell as a percentage of the reference price. For example, the bank may offer its entire holdings of the pool for prices at or above $105 \%$ of the reference price, but only three-quarters of its portfolio at $100 \%$ of the reference price, and one-half of its portfolio at $95 \%$ of the reference price. For each pool, banks are constrained to offer a particular fraction of their entire holdings of the pool of securities. That is, the bank cannot "cherry pick" by offering a larger quantity of one security that the bank believes is especially over-priced by the model that determined reference prices. This structure limits the adverse selection problem that the aggregator bank faces in purchasing assets from better informed banks-the tendency of the banks to more eagerly offer securities that are overpriced.
Reference-price auction. Prices are determined in a transparent and competitive reverse auction. You may have thought that the Treasury was no longer considering the use of auctions. However, Secretary Geithner stated, "Our objective is to use private capital and private asset managers to help provide a market mechanism for valuing these assets." Market mechanism means "auction." The banks compete to sell their portfolios of troubled assets. Here is what we mean by a reverse auction. Related pools are auctioned at the same time in a simultaneous descending clock auction. For each pool, there is a "price clock," indicating the tentative price of each pool, as a percentage of the reference price. Bidders (the banks) express the quantities they wish to supply at the current prices. The price is decremented for each pool of securities that has excess supply, and bidders again express the quantities they wish to supply at the new prices. This process repeats until supply is made equal to demand. The tentative prices and assignments then become final. As an example, if a pool clears at $95 \%$ of the reference price and the reference price for the particular security is 65 cents on the dollar, then each bank offering the security is paid $95 \% \times \$ 0.65$ for every dollar of facevalue that is sold. Details of the design are presented in a working paper we wrote last fall that is available online.

\section{ADVANTAGES OF THE AGGREGATOR BANK}

The aggregator bank as presented above I has several important advantages relative to TARP.

- Focused participation on the supply side. Bank participation is limited to those banks who appear strong enough to save. The securities purchased are limited to primary assets and whole mortgages, and not derivatives.

- Broad participation on the demand side. Demand consists of both public and private capital. Moreover, the private capital is not restricted in any way. This maximizes the money available to purchase the troubled assets. The floor on losses of each pool motivates private capital to participate. Favorable lending terms may also be used to leverage private capital.

- Avoids adverse selection. The approach mitigates adverse selection by using reference prices, based on state-of-the-art modeling, and limiting each bank's supply offer to a 
share of the bank's holdings for the particular pool of securities. Mitigating adverse selection-the problem of buying more of securities that are overpriced-protects both the taxpayer and the private investors in the aggregator bank. Importantly, reference prices play a limited role-to account for differences among securities within a pool. Absolute prices are determined in the auction.

- Transparent price determination. Securities are purchased in a transparent and competitive reverse auction. This protects both taxpayers and private investors. In addition, and perhaps more importantly, the process jumpstarts the secondary market for securities by determining and revealing true market prices for each security. This price determination will create immediate liquidity in the securities, and push auction prices up from fire-sale prices to market prices that better reflect the hold-to-maturity value of the securities. The competitive, rule-based process also avoids discretion, and the resulting lobbying, favoritism, and corruption.

- Private management of purchased assets. Since the government remains a minority shareholder, the aggregator bank will rely primarily on private-sector management of the purchased assets with the oversight of the government, as a major minority shareholder.

- Readily implemented. All of the elements of the aggregator bank are standard and wellunderstood. The reference price approach has already been studied by the Treasury, since the fall. Also the auction methodology is commonly used in practice and was experimentally tested in the fall by us.

The aggregator bank must have an explicit charter that limits what it can do. It can buy assets as described in its charter. It can manage the purchased securities, determining what and when to sell. It cannot engage in other investments or take positions in derivative securities. These limitations protect private investors, and help assure that the aggregator bank achieves its mission at least cost to the taxpayer.

Letters commenting on this piece or others may be submitted at http://www.bepress.com/cgi/ submit.cgi? context $=$ ev .
REFERENCES AND FURTHER READING

Ausubel, Lawrence M. and Peter Cramton (2009) "No Substitute for the 'P'-Word in Financial Rescue," The Economists' Voice, 6(2): Art. 2. Available at: http://www.bepress.com/ev/vol6/ iss2/art2.

Ausubel, Lawrence M. and Peter Cramton (2008) "A Troubled Asset Reverse Auction," Working Paper, University of Maryland. October 5. Available at: http://www.cramton.umd.edu/ papers2005-2009/ausubel-cramton-troubledasset-reverse-auction.pdf.

Ausubel, Lawrence M. and Peter Cramton (2008) "Auction Design Critical for Rescue Plan," The Economists' Voice, 5(5): Art. 5. Available at: http://www.bepress.com/ev/vol5/iss5/art5.

Ausubel, Lawrence M., Peter Cramton, Emel Filiz-Ozbay, Nathaniel Higgins, Erkut Ozbay, and Andrew Stocking (2008) "Common-Value Auctions with Liquidity Needs: An Experimental Test of a Troubled Assets Reverse Auction," Working Paper, University of Maryland. December 14. Available at: http://www.cramton.umd. edu/papers2005-2009/acfho-common-valueauctions-with-liquidity-needs.pdf. 